I admit that I liked some of the maps in Cartography Design Annual \#1 much more than others, and a few just didn't seem worthy of their place in the book in comparison with the rest of those chosen. Even with maps, it would seem, beauty is in the eye of the beholder. But for the true cartophile, there is plenty to behold in this book.

\section{Cartographic Relief Presentation}

By Eduard Imhof

ESRI Press, Redlands, California, 2007

436 p., 14 color plates, bibliography, index.

ISBN: 9781589480261

soft-cover $\$ 59.95$

Reviewed by Dawn Youngblood, PhD

Southern Methodist University, Dallas

Swiss geographer Eduard Imhof's classic text is once again available in English. Within the discipline of cartography, few works are considered classics and few of those remain relevant beyond the transition to GIS mapping. Imhof's text on relief representation, however, can still be viewed as a masterpiece. Imhof combined intellect and graphics in the solution of map design problems; his mission was clearly to improve the precision and readability of maps. He writes on page 359 of this volume that "Only simplicity provides a lasting impression," and what makes Imhof a master cartographer is his ability to take a large amount of complex topographic data and transform it into something not only simple in its ability to be interpreted but beautiful as well.

Eduard Imhof (1895-1986) was a professor of cartography at the Swiss Federal Institute of Technology in Zürich from 1925 to 1965 and devoted his career to raising the standards of map design. He is best known for his relief shading work and mountain cartography. Considered the founder of modern academic cartography, Imhof was one of the people responsible for the inspirational and accurate Swiss national maps. In 1965, his breakthrough book, published in German, Kartographische Gelande Darstellung, filled a need in cartographic instruction by offering guidelines for properly rendering terrain in maps of all types and scales. The book was translated into English in 1982 for Walter de Gruyter publishers of Berlin as Cartographic Relief Presentation, and the translation served to expand its influence globally. Cartographic Relief Presentation was an expensive book with a limited press run that made it a rare find until this new ESRI Press edition was issued. The reissue should benefit mapping professionals, scholars, scientists, and students alike, whether their maps are drawn by traditional means or with the aid of a computer. This new edition of Cartographic Relief Presentation preserves Imhof's insightful commentary and analytical style through the application of sparse editing. All the color maps, aerial photographs, and instructive illustrations are faithfully reproduced. It should come as no surprise that gorgeous full-color cartographic plates used as examples for the text feature the geographer's Swiss homeland, particularly the Alps. In the 1982 English edition published by de Gruyter, the plates were loose and were included in a sleeve in the back of the volume. In the ESRI Press edition, they are bound into the back. Cartographic Relief Presentation was among the essential mapping and graphical design books of the twentieth century. Many such volumes suffer the "out of sight, out of mind" syndrome when they fall out of print, but the recognition by the new publishers of the continuing relevance of Cartographic Relief Presentation for the twenty-first century has saved Imhof's work from a similar fate.

The sixteen chapters guide the reader from the "Topographic Foundations" of Chapter 2 through to the "Interplay of Elements" in Chapter 14, with additional observations and future developments in Chapters 15 and 16, respectively. Chapter 1 is a fifteen-page history of cartographic relief presentation beginning with the earliest known map-an earthenware plate from Mesopotamia some 4,400 years old. While brief, the history is thorough and does not stray from the specific topic of relief presentation. Whether the reader is interested in history or not, the demonstration of knowledge gives him or her a sense of the deep and thorough scholarship Imhof devoted to his task. The author, for instance, credits Leonardo da Vinci for first showing relief forms individually and continuously related, as if seen in an oblique bird's-eye view.

Chapter 2 lays the topographic foundations of relief presentation from classic survey methods, through issues regarding accuracy, to the use of general or derived maps at smaller scales as working bases. Chapter 3 goes deeply into general principles on the study of topography including landscape drawing, aerial photography and its interpretation, field reconnaissance and identification, rectification, and an excellent explanation of the differences between aerial photographs and maps. The chapter also explores binocular viewing in stereo pairs before ending with a brief but clear statement of the importance of the cartographer in advancing scientific knowledge as part of a reciprocal relationship with geomorphologists.

Chapter 4 is devoted to the theory of colors. One look at the beautiful reproductions of Imhof's own work found among the color plates will encourage the cartographic student at any level to read this chapter. His use of hypsometric tints and colors demonstrates his mastery of composition and harmony using strict 
standardization. After quickly reviewing the chemical and physiological theories of color, Imhof reviews the psychological theory of color. Following a classification of colors, Imhof offers specific advice on effective color combinations, demonstrating the practicality behind understanding the theory.

In Chapter 5, Imhof explores the general problem of relief presentation, which basically stems from attempting to represent a three-dimensional surface on a two-dimensional plane. He further explains the differences between a map and a picture, and discusses the goals of the cartographer challenged to present relief. Spot heights and soundings and their significance are covered in Chapter 6. As in other chapters, but particularly in this one, exacting tables inform the reader of precise measures, such as minimum type sizes (for spot height values) for sheet maps by scale.

Chapter 7 is devoted to a short study of skeletal lines, which can serve either as a constructional aid or as an independent form of terrain representation. The significantly lengthier Chapter 8 offers a detailed study of contour lines in just under forty pages. Again, precise tables and illustrations guide the learner in selecting every detail while the text addresses the resolution of various problems, such as what to do when data is absent.

It should come as no surprise that the longest chapter in Imhof's book is devoted to shading and shadows. Chapter 9 progresses from general aspects and graphic procedure through to oblique hillshading with a computer some fifty pages later. Examples of shading and shadows are prolifically and expertly illustrated using multiple angles and degrees. Chapter 10 covers hachures and other related techniques while Chapter 11 devotes nearly fifty pages to rock drawing, including a critical examination of the different methods and prescriptions for which is best for various scales.

Among the initial decisions any cartographer must make is selecting symbolization. Imhof's Chapter 12 refers strictly to topographic symbolization, in keeping with his overall theme. Chapter 13 explores the purpose and possibilities of area color tinting in maps, applying the lessons learned in the earlier chapter on color theory. Chapter 14 explores the nature and effect of the interplay of elements for varying scales of map. In it, Imhof lays out his now classic techniques for allowing clarity of interpretation among layered elements, such as contour lines and text. Chapters 15 and 16 are devoted to map reproduction techniques and to future developments, respectively. Since this is a classic work, these last chapters, while enjoyable and brief, may be the ones of least practical use to the cartographer.

The ESRI Press edition of Cartographic Relief Presentation was edited by H.J. Steward for clarity and con- sistency and is intended to be an affordable volume for the modern student of cartographic method and theory. The result is a study of cartographic relief presentation that is both approachable and at moments profound. The careful balance of words and images conveys the principles of cartographic expression under consideration as clearly as the relief on an Imhof map of the Alps.

\section{GIS Tutorial for Marketing}

by Fred L. Miller

2007 ESRI Press; Redlands, California

432 pages, with graphics on every page

Includes 180-day trial copy of ArcGIS Desktop 9.2

Software on DVD

Includes a data CD

$\$ 79.95$ US, Softcover, spiral bound

ISBN 978-1-58948-079-7

\section{Reviewed by Eva Dodsworth, Geospatial Data Services Librarian, University of Waterloo}

Written specifically for the undergraduate marketing curriculum, GIS Tutorial for Marketing is a nine-chapter, hands-on GIS exercise book that guides the user step by step through course-related business scenarios. With each chapter representing content taught in marketing courses, students gain complementary GIS knowledge through theory and practical exercises using ArcGIS 9.2 software. No previous GIS knowledge is necessary, as the book provides an introduction and guided overview of the software program. Although targeted for marketing students, this tutorial makes an excellent resource for professionals in the marketing and business industries. The sample data included with the book provide professionals with a taste of some of the detailed demographic and consumerbased data collected and made available commercially. The book also acts as a comprehensive GIS reference manual and an overall how-to GIS tutorial for those new to ArcGIS. GIS Tutorial for Marketing provides readers a broad-based, hands-on resource for learning how to use GIS tools in making marketing related decisions.

The author, Dr. Fred L. Miller, is Professor of Marketing and Telecommunications Systems Management at Murray State University. He has authored many articles on marketing GIS and is the recipient of the 2001 Marketing Education Review Best Article Award. His technical knowledge in GIS and professional experience in teaching marketing courses have produced a resource unavailable until the release of this book. Dr. Miller clearly illustrates the value of GIS technology in 